\title{
The need to engage with citizen scientists to study the rich fungal biodiversity in South Africa
}

\author{
Marieka Gryzenhout
}

${ }^{1}$ Department of Plant Sciences, University of the Free State, Bloemfontein, 9301 South Africa; corresponding author: gryzenhoutm@ufs.ac.za

Abstract: Fungi are a marginal interest group for the South African public even with the recent boom in nature guides covering diverse topics. However, fungi are not a marginal group in any ecosystem on Earth, and have vital ecological functions with significant positive or negative impacts on the lives of humans. The reasons for the obscurity of fungi, are that fungi are not well-known, often negatively perceived and not well publicized. Yet strong interest exists from laymen to diverse biologists. These enthusiasts are frustrated by a lack of information and expertise. South Africa has an incredibly rich diversity of fungi but there are no active experts cataloguing and describing these fungi, especially the groups the public encounters. This is a problem also experienced by many other African countries. Planned and focused efforts including citizens will contribute to the needed stimulation, promotion and funding of research in mycology in South Africa.

Keywords: checklists, collections, education, mycology, training

\section{INTRODUCTION: FUNGI}

Fungi (Figs 1,2) are a group of eukaryotes representing a unique kingdom in the Tree of Life (Kendrick 2001). Representatives from two other kingdoms, i.e. Oomycota in the Straminipila, and Myxomycota in the Protozoa, have morphological similarities to the fungi and were traditionally dealt with by those studying fungi (mycology), which remains the case today. Members of the fungal kingdom are immobile and are defined by the formation of threadlike structures called hyphae that form the different tissues of the fungus, an adsorptive metabolism and reproduction with spores of diverse shapes formed by morphologically different structures (Boddy \& Coleman 2010). They represent diverse general groups commonly called mildews, moulds, lichens, mushrooms, rusts, smuts, cup fungi, and yeasts.

In nature, fungi occur in every niche imaginable, including ice fields, deserts, rocks, tropical forests, any form of water, soil, air, on diverse organisms such as plants, animals and arthropods, and in decaying organic matter. In these diverse substrates they have various ecological roles, such as breaking down organic matter for recycling, forming unique mutualistic relationships with their partners, or as pathogens killing or causing disease of their hosts. Fungi impact on humans as pathogens of humans, livestock and crops, contaminants of food and living environments, or they are instrumental in making bread, alcoholic beverages or medicine. The biodiversity of fungi and the complexity of their combined or individual functions, are too wide for individual mycologists to fully study in one lifetime.

Fungi are largely microscopic but have forms that are visible with the naked eye by trained as well as untrained eyes. Estimates put the number of species in South Africa alone to at least 172000 species, taking into account a number of niches but not all (Crous et al. 2006). The estimated number of species in the world is considered to be at least 1.5 million and probably 3 million (Hawksworth 2012). These most likely are all underestimates due to the numerous niches inhabited by different communities of fungi such as soil and the guts of insects, and because studies continue to uncover yet more unknown species and even novel niches. This represents a taxonomic dilemma with an ever-dwindling number of systematists who are able to describe or at least characterize these fungi, even if using only molecular tools (Taylor \& Hibbett 2013).

Fungi, together with numerous other microscopic organisms (Cowan et al. 2013), are often treated by users of species names such as ecologists, conservationists and quarantine authorities, as a black box representing a group of organisms impossible to deal with (Gryzenhout $e t$ al. 2012). This is true throughout the world, and the case in South Africa. This is compounded by the ecological impact of fungi being largely unstudied even if fundamental (Gryzenhout et al. 2010). Because this impact is difficult to measure, it is thus easily ignored and omitted from conventional ecological surveys. However, biodiversity, ecological surveys and the systematics of fungi are equally important to study as for other organisms such as plants and larger animals, and equally possible. Although funding available for biological surveys continues to be in a state of flux, biodiversity awareness for fungi has been increased in South Africa over the past two decades.

As with larger animals and plants, it is possible to engage with members of the public who are interested in various strange or unknown mushrooms they encounter. Larger fungi are incredibly photogenic, enigmatic to simply strange, and various beautiful books and websites exist (e.g. Lockwood 2002; http://www. taylorlockwood.com). Fungi are also important in the traditions of many human cultures (a field known as ethnomycology), including those of numerous African countries (Gryzenhout et al. 2012). It is thus possible to include fungi in greater ecological studies by scientists other than mycologists. However, in South Africa knowledge of our fungi is difficult to access, and the interest in our fungi is relatively low; further, the number of professional mycologists with the needed expertise, time and capacity, is critical. This commentary explores the possibility of engaging with the public to enhance the image of mycology and to also generate scientific data in an 

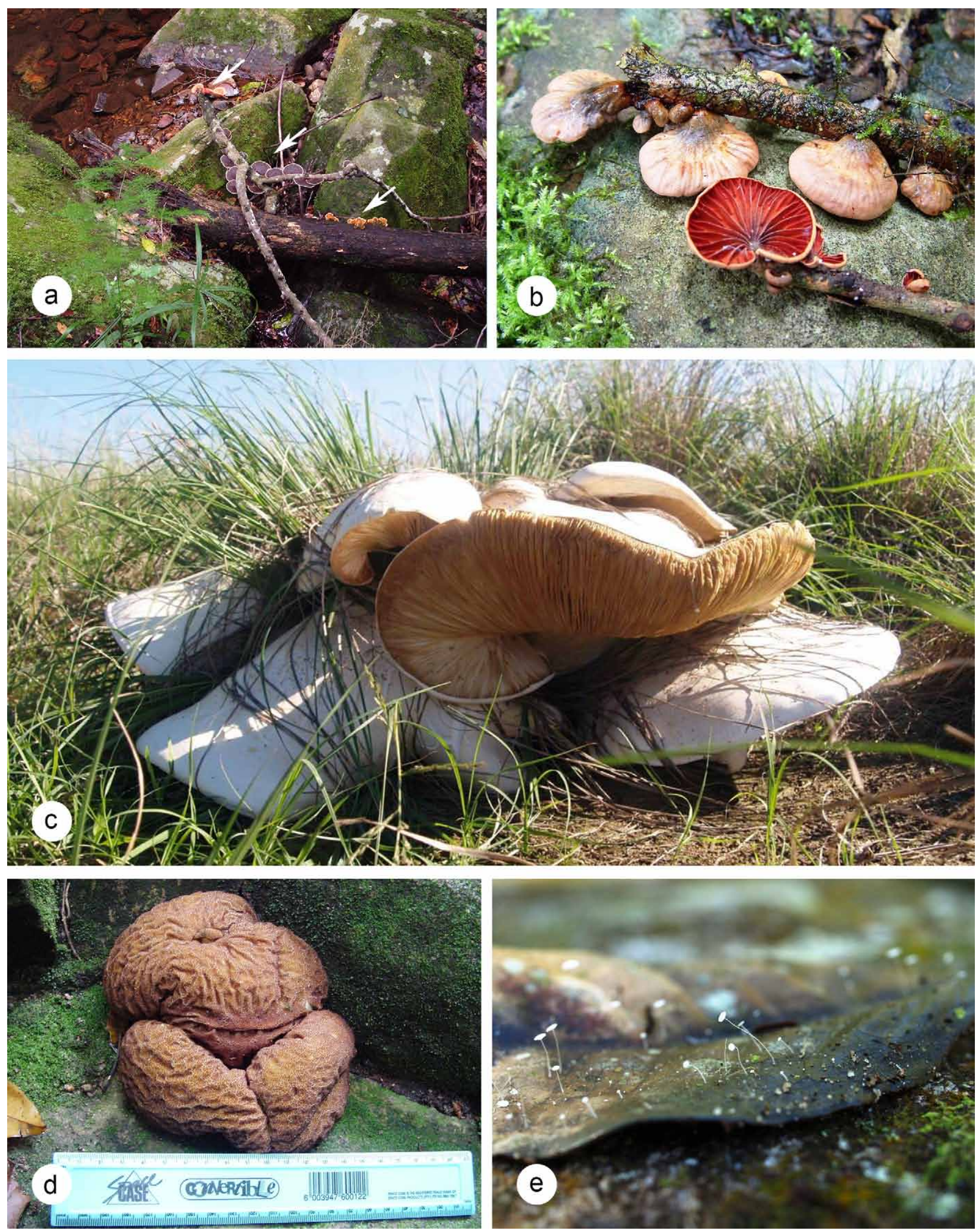

Fig. 1. Various types of larger fungi. (a) Three types of bracket fungi commonly found in forests; white arrow, the tropical cinnabar bracket (Pycnoporus sanguineus); grey arrow, the black cork polypore (Trametes cingulata); dotted arrow, the false turkey tail (Stereum ostrea). (b) Anthracophyllum archeri, a bracket fungus from Mpumalanga identified from an Australian field guide. (c) The gigantic Macrocybe lobayensis first discovered by a field guide user in the iSimangaliso Wetland Park, but remained unknown until the identity was obtained from an Australian mycologist. (d) An unknown fungus, still unidentified. (e) Minute basidiomes of a possible Mycena sp. on a rotting leaf. 
effort to address these problems. It is my hope that this document will be useful to promote mycology among the public and circles where fungi are not as well-known.

\section{THE USEFULNESS OF FIELD GUIDES AND BIODIVERSITY DATA}

Field guides are vital for various biological disciplines. They do not only function to be used by laymen interested in what is in their garden or what was seen during a recent hike. They are equally sought after by professional biologists seeking to identify specimens, those exploring a different niche or geographical area, undertaking biodiversity and ecological impact assessments, or involved in multidisciplinary investigations for instance where hosts of organisms, such as plants, must be identified. They are vital in the training of students and their research. More than one guide for a particular organism group is often useful to showcase other plants not previously included, to provide additional information and illustrations, or is more suited to different individual preferences.

Over the past decades a flurry of diverse nature guides has been published in South Africa. For some biological groups more than one specialized nature guide exists. These originate from scientific experts who are professional biologists in universities, museums or research institutes, or those working in the field, such as conservationists and ecological officers. Often, however, citizen scientists or groups doing these out of passion and as a hobby, also drive, write or significantly contribute to these guides. A good example in South Africa is the numerous publications brought out by the Lepidopterists' Society for Africa, Lepsoc (http://www.lepsoc.org.za/publications/ books-posters-ebooks//).

Unfortunately the same is not necessarily true for fungi. Two currently available field guides (Branch 2001, Gryzenhout 2010) can be obtained on the mushrooms of South Africa, and two previous guides (Levin et al. 1987, van der Westhuizen \& Eicker 1994) exist but are out of print. However, these guides only contain a small fraction of the fungi known in South Africa. There is no current checklist of all, or even some, of the fungi occurring naturally, especially of native fungi and those that are not necessarily in a collection. Those professionals needing fungal biodiversity data for national biodiversity initiatives or where ecological data needs to be generated, often lament this state of affairs.

There are few focused, continuous and large-scale surveys with published data to add to our knowledge of the native fungi of South Africa, especially when compared to other biological disciplines. This is especially true for the larger fungi. However, surveys on specific fungal groups, often microscopic forms, are still undertaken by current researchers (e.g. Marincowitz et al. 2008). No professional mycologist is, however, in the position of being able to only undertake biodiversity surveys and describe fungi, as has been done in some other biological disciplines, since funds for this must always be channeled from applied research these mycologists are employed to do. Expertise and time for descriptions are dwindling. There are now very few mycologists who can devote significant portions of their time to assist citizen scientists in organized efforts to generate such data, even if the capacity and interest exists. These facts have been summarized by the South African Fungal Diversity Network (2013).

What are the reasons for this information dilemma? There is a limited number of mycologists in South Africa, and very few opportunities of positions. Existing research is often restricted or focused in certain research topics or groups of fungi, and a limited number of surveys can only cover a small portion of the fungal diversity of South Africa. Many fungi are also seasonal organisms that occasionally need specialized environmental conditions to produce sporophores, hence efforts to find more samples of scarce species can be serendipitous. This situation is compounded by fungi being so biologically and morphologically diverse, that the sampling and expertise to collect the full taxonomic diversity does not overlap. Collecting is often quite specialized, needing isolations and purifications on artificial growth medium that are complex and time consuming (Fig. 3b). No less than 21 specialisms required to undertake an intensive fungal inventory have been recognized (Hawksworth et al. 1997), and diverse methods and approaches are required (Mueller et al. 2004).

Despite these challenges, the current state of mycology in South Africa at the moment is not that dire. Mycology has a rich history in South Africa with a dedicated National Collection and a number of internationally known and active mycologists (Rong \& Baxter 2006). Information is generated and published in reputable international, scientific, and specialized journals. However, most of the current scientific expertise currently available in South Africa focuses more on the microfungi, particularly those concerned with tree diseases, while the larger fungi and lichens that can be included in nature guides, are poorly studied with needed macrofungal and lichenological expertise for assistance to the public becoming less.

\section{IS THIS GOOD OR BAD?}

Is it necessarily bad that there is not a consistent series of field guides to the fungi of South Africa and no current checklist? International cutting-edge research in mycology has been, and still is, being produced by South African mycologists. A very strong knowledge base on fungal diseases of plants, humans and animals exists with previous exploratory research on fungi reported (e.g. Crous et al.2000, 2006). Furthermore, the systematics of some fungi in South Africa is published and highly developed. Since it is impossible to cover the entire diversity of fungal groups, it is in any case a daunting task to satisfactorily study all fungi in South Africa. The National Collection of Fungi is still active and continuously improving its collections, infrastructure, biodata, and initiatives. All of these activities indicate that some level of funding and effort can be used to produce data. Furthermore, a level of awareness has also begun in official circles regarding the importance and presence of fungi with the hopeful need to support mycological studies.

A great deal of excellent mycological research in South Africa has focused, and still do, on applied issues such as plant and forest pathology, food safety, food mycology, industrial mycology, and the role of fungi in the health of humans and animals. Undoubtedly this is because that is where the funds are. The benefit of this is that mycologists know very well what the applications of their work are, and how exploratory work can be utilized, for instance, to create new opportunities in biotechnology, and aiding crop and food safety.

Unfortunately the pressure to deliver applied research and to successfully procure funds leaves little space for basic exploration and characterization of our rich mycological biodiversity. This includes those willing 

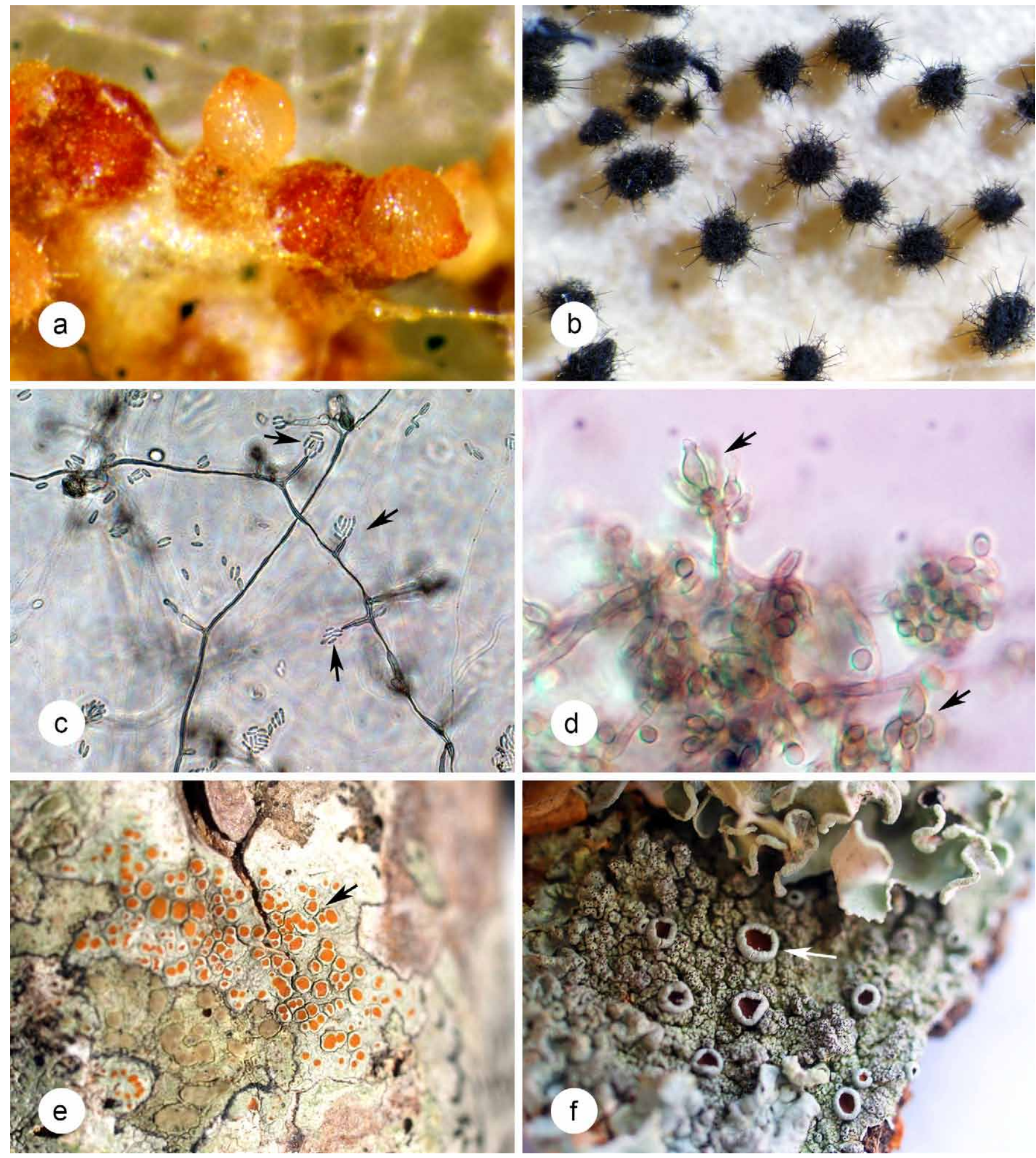

Fig. 2. Other forms of fungi besides larger mushrooms. (a) Minute sporophores on an artificial growth medium c. $200 \mu \mathrm{m}$ diam; Fusarium neocosmosporiellum. (b) Minute sporophores (ascomata) with delicate branched appendages; Chaetomium funicola. (c-d) Filamentous spore producing forms (arrows) of the genera Fusarium (c) and Scopulariopsis (d). (e-f) Sporophores (apothecia; arrows) of the fungal partner of two lichenized fungal species.

to do it, while others are often simply not interested. This results in that although passionate about fungi, many mycologists do not have the time, capacity or funds for continued exploratory and descriptive work, or even to train and assist others to do so.

Past biodiversity studies of fungi have not necessarily been continued, and thus represent occasional and fragmented reports. Fungal data also need to be presented more in fields such as ecology, biodiversity, and conservation, where exploratory and biodiversity work is still being done. This lack of representation contributes to fungi being generally illfunded compared with larger animals and plants, and that the presence and usefulness of fungal data are not understood or appreciated by non-mycologists. There are consequently very few service points devoted to assist users of fungal names in 
ecology, biodiversity, conservation, and in the public sector.

The lack of elementary biodiversity data in the form of available checklists, comprehensive scientific literature such as monographs, databases and the more user-friendly nature guides, unfortunately does have implications. The continued lack of data for users, and their inability to understand, explore and note the presence of fungi, may contribute to fungi remaining obscure and unfunded. Without any type of list, fungi simply cannot be included in biodiversity databases. Whereas now we can still make a case that it is necessary to produce such data and continuously add to the deficit we already have by means of new surveys and publications, the time may come when this will not be enough anymore. The need to promote fungi may later depend more on the availability of data and visible efforts to expand this, than on the continued absence of data, because this may be seen as inactivity and unreliability of the community. The inability of users readily to obtain fungal data may later lead to continued exclusion of such data from ecological services, whereas continued initiatives, even if limited, would have promoted mycology more. Therefore, while currently there may be a heightened awareness of general biodiversity in South Africa, if mycology is not able to utilize this momentum it may be more difficult in future.

\section{CAN WE REMEDY THIS?}

Training of future mycologists passionate about fungi continues to be the duty of current professional mycologists. However, it is unlikely that the near future will see a boom in the number of mycologists able to undertake such work unless the importance of mycology becomes recognized in education circles and with the promise of adequate work opportunities. This foundation is crucial to ensure that a sound knowledge base remains available.

Currently very limited capacity exists to deal with gaps in our knowledge of South African fungi. Here, lichens (Fig. 2e-f; a mutualistic association between fungi and algae or cyanobacteria) and larger fungi such as mushrooms, are of most concern, because they are what the public observes and wonders about. Currently there is no mycologist (or lichenologist) active in research, describing new species, collecting throughout South Africa, and publishing works for non-mycologists. Other ways have to be sought to generate novel data, or even to collate existing data.

Active collaborations with experts based in other countries can be sought, and they can visit South Africa, collect and publish their data following the appropriate regulatory procedures. Many such experts have their own, successful public awareness initiatives and engagement with appropriate authorities. However, random visits will not necessarily meaningfully contribute to the dilemma of data, unless these visits are communicated, co-ordinated, and fed into our national initiatives.

Unless more professional mycologists can be trained, knowledgeable citizen scientists will be crucial to the generating of data. From my personal experience and interactions with members of the public (Fig. 3a), it is clear that there are resourceful, passionate, and knowledgeable people with an ardent interest in fungi. Many of them are excellent photographers that take meaningful photographs once they know what is important to look for. An example is the first report of Entoloma virescens from South Africa, a bright blue mushroom better known from Australasia, by a citizen scientist (Carbutt \& Gryzenhout 2011).

Often people who did not really know anything much about fungi, became intrigued once properly introduced to them. This is usually because they did not know that fungi were so common, diverse (especially when introduced to microfungi as well), ecologically important or impacting so much on the lives of humans. During "fungal walks" or when dealing with queries, it is unfortunately frustrating that the majority of finds are of unknown identity. However, this can be used to eloquently illustrate how little we know of our indigenous fungi, and the need to study them.

Members of the public contribute tremendously towards various biological sciences in South Africa, and examples include CREW, LepSoc and Toadnuts (Young 2010, Anon. 2013). Members of the public, either independently or together with experts, have been able to establish meaningful datasets useful for science. This situation can be applied to mycology, because there are plenty of success stories for amateur science initiatives in mycology in other countries, where the public contribute distribution and ecological data for target fungi (e.g. Fungimap in Australia; http://fungimap.org.au) and several local societies compile biodiversity data (e.g. the North American Mycological Association (NAMA); http://www.namyco.org). However, without guidance, efforts will not be co-ordinated and focused, nor will these be available to the greater scientific community.

\section{CAN THE PUBLIC DO IT ON THEIR OWN?}

For fungi, expert assistance is unfortunately essential. Mycology is a rather unusual, unknown discipline not given full exposure at school and often not even at tertiary level. Students are usually captured only at post-graduate level. There are too few guides to invite extensive study of local fungi, and other field guides produced in other countries often have to be used because there simply is no complete guide for visual identification. The most comprehensive South African guide (van der Westhuizen \& Eicker 1994) contains at most 160 species, a small percentage of the estimated species in South Africa). There are no checklists against which to compare findings, and few experts to compile these. It is usually also unfortunate that often a level of microscopy will be needed, for critical identifications of even many larger fungi.

The lack of a species name need not be a hindrance. In the most recent field guide, Gryzenhout (2010) used a system of grouping fungi into their common name groups. If a member of the public encounters a large fungus that is unknown and not found in any existing guide, it can at least be referred to one of these general groups. That is to some degree satisfying, since it is not then a completely unknown fungus anymore; that step may also facilitate further identification by using other guides, or by sending the specimen to an appropriate expert.

The most current field guide (Gryzenhout 2010) is set up in a standard format that should be conducive to add more species in future. The field guide also did not depend only on the author, but was a combined effort from members of a network the author initiated, and who sent useable photographs the author would not easily have been able to obtain on her own. Although mushroom guides are seen as low volume overturn publications by publishers, it is hoped that the latest publication can be 

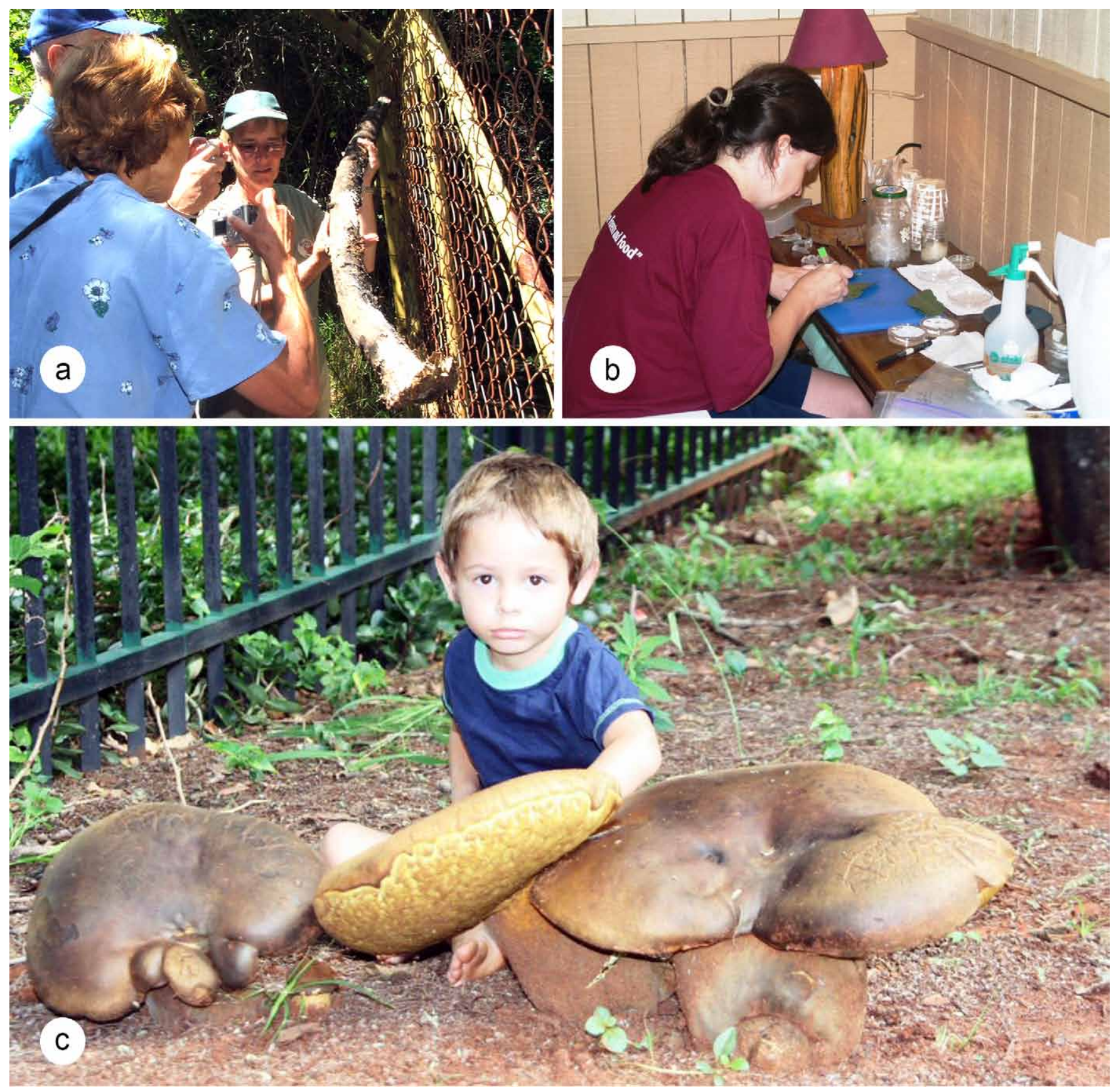

Fig. 3. (a) Eager participants of a fungal walk photographing fungi. (b) Typical isolation process for fungi after a collection trip. (c) Queries of unusual fungi are often sent by members of the public (in this case representing Phlebopus sudanicus, the bushveld bolete).

expanded by additional volumes containing different fungi, and not merely showing the same species as those in previous guides.

\section{WHAT WOULD THE AIM OF CITIZEN INVOLVEMENT BE?}

Efforts to produce future field guides and public involvement in mycology should not only be there to feed the curiosity of the public, even though that in itself is an admirable goal. Feedback and input from the public can be used to produce a source of sustainable data for mycology. The public have the potential, with suitable guidance, to collect distribution data and produce photographic records, which most likely would not be attainable otherwise. The most enthusiastic may even be trained to collect and process specimens that can be lodged at the National Collection of Fungi for future study.

This would be in vain if not used to produce a meaningful, sound database of names, records, ecological data, and images accessible in future. Ideally this should be linked to service current scientific questions, initiatives, or deficits in the field of mycology. It would also be used where mycology may service other disciplines such as ecology, conservation, or greater national goals such as the sustainability of agricultural and natural resources, or studies in climate change.

Field guides, e-guides, or at least a photographic database, will be essential to collect and coordinate accurate data. It is likely that material for future field guides can already be produced. Creating awareness and engagement will be important to 
ensure that future publications will be economically feasible.

A number of interactive, online database tools are available where data and images can be compiled (Silvertown 2009). Many of these were created to aid citizen scientists and contribute to professional science. Examples relevant to South Africa include iSpot (The Open University; http:// www.ispot.org.za), a citizen identification service or survey tool developed to share observations, to obtain identifications (with varying levels of confidence), and to catalogue data and locations. Data are linked to other internet-based biodiversity databases. Results can also be published or are citable. A South African page including fungi has been initiated, and currently all data contribute to the biodiversity initiatives of SANBI (South African National Biodiversity Initiative, http://www.sanbi. $\operatorname{org} /$ ).

A novel Facebook page, Mushrooms of Southern Africa (https://www.facebook. com/groups/MushroomsSouthernAfrica/) has recently been initiated by the Animal Demographic Unit (http://adu.org.za/) at the University of Cape Town. This unit has already initiated several citizen science groups where a diverse community of members has successfully compiled biodiversity data for various biological groups. The Mushrooms of Southern Africa facebook page was initiated in the first half of 2014, and had already grown to a membership of 1938 by 18 September 2015 . This indicates that there is a large interest in the public to learn more about fungi and to get sightings identified.

The Animal Demographic Unit contributes significantly to creating distribution maps of several types of organisms in southern Africa. Similarly, a Mushroom Map database is currently being developed for the future creation of distribution data, with the input from a number of enthusiasts. With known species lists compiled from currently available fungal field guides, it is thus possible to actively use members of this page to compile curated observational data for species.

\section{CONCLUSION}

Fungi should become more visible and be promoted more. Information regarding the fungi occurring in South Africa should be available for a variety of users. Knowledge should be built in such a way that it can easily be expanded and accumulate in future. Such knowledge should be scientifically sound, and its accessibility should be permanent.

With the help of the scientific mycological community, the public can contribute meaningfully and can be trained. Members of the public interested in fungi are hungry and enthusiastic, but they need a champion (or champions) to provide assistance and continued impetus. Hard work and commitment will be necessary, or at least the necessary environment that enables these activities. It may well be possible that through such activities, the foundation of mycology in South Africa may be strengthened and may take mycology to the next level where it can be more competitive with other biological disciplines.

\section{REFERENCES}

Anon. (2013) Citizen science \& the western leopard toad. Quest 9: 18-21.

Branch M (2001) First Field Guide to the Mushrooms of South Africa. Cape Town: Struik Publishers.

Boddy L, Coleman M (2010) From Another Kingdom: the amazing world of fungi. Edinburgh: Royal Botanic Garden Edinburgh.

Carbutt C, Gryzenhout M (2011) The all-blue agaric: a new record for South Africa. Veld and Flora 97: 34-35.

Cowan DA, Rybicki EP, Tuffin MI, Valverde A, Wingfield MJ (2013) Biodiversity: so much more than legs and leaves. South African Journal of Science 109: 8-16.

Crous PW, Phillips AJL, Baxter AP (2000) Phytopathogenic Fungi from South Africa. Stellenbosch: University of Stellenbosch Printers.

Crous PW, Rong IH, Wood A, Lee S, Glen HF, Botha W, Slippers B, De Beer WZ, Wingfield MJ, Hawksworth DL (2006) How many species of fungi are there at the tip of Africa? Studies in Mycology 55: 13-33.

Gryzenhout M (2010) Pocket Guide: mushrooms of South Africa. Cape Town: RandomhouseStruik.

Gryzenhout M, Jefwa J, Yorou NS (2012) The status of mycology in Africa: a document to promote awareness. IMA Fungus 3: 99-102.

Gryzenhout M, Roets F, de Villiers R (2010) Fungal conservation in Africa. Mycologica Balcanica 7: 53-58.

Hawksworth DL (2012) Global species numbers of fungi: are tropical studies and molecular approaches contributing to a more robust estimate? Biodiversity and Conservation 21: 2425-2433.
Hawksworth DL, Minter DW, Kinsey GC, Cannon PF (1997) Inventorying a tropical fungal biota: intensive and extensive approaches. In Tropical Mycology (K K Janardhanan, C Rajendran, K Natarajan \& D L Hawksworth, eds): 29-50. New Dehli: Oxford \& IBH Publishing.

Kendrick B (2001) The Fifth Kingdom. $3^{\text {rd }}$ edn. Newburyport, MA: Focus Publishing.

Levin H, Branch M, Rappoport S, Mitchell D (1987) A Field Guide to the Mushrooms of South Africa. Cape Town: C. Struik (Pty.) Ltd.

Marincowitz S, Crous PW, Groenewald JZ, Wingfield MJ (2008) Microfungi occurring on Proteaceae in the Fynbos. Utrecht: CBS-KNAW Fungal Biodiversity Centre.

Mueller GM, Bills GF, Foster MS (eds) (2004) Biodiversity of Fungi: inventory and monitoring methods. Amsterdam: Elsevier.

Rong IH, Baxter AP (2006) The South African National Collection of Fungi: celebrating a centenary 1905-2005. Studies in Mycology 55: $1-12$.

Silvertown J (2009) A new dawn for citizen science. Trends in Ecology and Evolution 24: 467-471.

South African Fungal Diversity Network (2013)

Fungi. In: A Biosystematics Research Strategy for the Algae, Animals, Bacteria and Archaea, Fungi and Plants of South Africa 2013-2018 (Victor JE, Hamer M, Smith GF, eds): 1-40. [SANBI Biodiversity Series no. 23.] Pretoria: South African National Biodiversity Institute.

Lockwood TF (2002) Treasures from the Kingdom of Fungi. Mendocino, CA: Taylor F. Lockwood.

Taylor JW, Hibbett DP (2013) Towards sequencebased classification of species. IMA Fungus 4 : 33-34.

van der Westhuizen GCA, Eicker A (1994) Field Guide: mushrooms of southern Africa. Cape Town: Struik.

Young S (2010) Monitoring threatened species in South Africa: a review of the South African National Biodiversity Institutes' Threatened Species Programme: 2004-2009. Pretoria: South African National Biodiversity Institute. 